\title{
INTERNAL MIGRATORY MOVEMENTS AND THE (NO) OPPORTUNITIES FOR SUSTAINABLE DEVELOPMENT IN THE REPUBLIC OF MACEDONIA
}

DOI: http://dx.doi.org/10.18509/GBP.2016.44

UDC: $314.15-026.48: 332.146 .2(497.7)$

\author{
Ass. Prof. Dr. Biljana Apostolovska Toshevska \\ M Sci. Marija Ljakoska \\ University of "Ss Cyril and Methodius"-Skopje, Faculty of natural sciences and mathematics, \\ Institute of geography, Skopje, Republic of Macedonia
}

\begin{abstract}
Internal migrations are interesting to be researched in function of creating a sustainable policy for population balanced, economic and spatial development.

These migratory movements in the 21 st century record a constant pace of progress. Focused mainly towards the urban municipalities and mainly towards the Skopje region, they are causing a basis for the analysis of the possible problems that occur due to the unequal distribution of population, disadvantages in the gender and age structure of the population in particular regions, which by itself dictates the biodynamics and the population basis of space. At the same time calls into the question for the possibilities of spatial and economic development of individual regions and especially the problem of overcoming the optimal opportunities for living in the city and the negative consequences on the environmental quality.

The paper aims to draw upon the opportunities and (no) opportunities for the sustainable development in different parts of the Republic of Macedonia in direct correlation with the impact of internal migration.
\end{abstract}

Keywords: migratory movements, Republic of Macedonia, sustainable development.

\section{INTRODUCTION}

Man is an eternal seeker and traveler in order to reach its self-realization in space. What has not been found, experienced or realized in one space, it seeks into another. That primordial power he carries in himself since the beginning of its existence until today. Only the motives, standards, requirements and ways of movement change.

The migration is a powerful strategy for people to overcome difficulties and continue to a better life, even when it comes to internal migration. Movement of the population from one space to another within a state is a normal phenomenon. There are always a pull and push factors that coordinate such movements. A leading motive is the search for a better quality of life, defined according the personal definition, life shaped to personally set standards.

The Republic of Macedonia within its area of $25713 \mathrm{~km}^{2}$, features an array of natural, socioeconomic and demographic spatial differences. It is these different natural geographic features, uneven economic development, various regional development potentials, different demographic characteristics of the space that dictate the pace, routes and type of internal migration flows.

The history remembers migratory flows from a plain area towards mountain areas for the purpose of protection from attacks and looting of road banditry, displacement due to 
disasters, the migrations of the population towards plain parts of the mountains due to a better access to roads and modern life. In the first half of the 19th century and the creation of the Chiflik system, because of the difficult life of the peasants, the emigration to the city increased, etc. [12].

The emphasized volume of internal migration flows from the villages to the cities took place in the sixties and seventies years of the last century as a result of the rapid socioeconomic development [5] and the mismatches between industrialization, deagrarization, migration and urbanization. Expressed migratory movements are recorded towards Skopje Valley and mainly to the capital Skopje. The most intensive immigration flow towards Skopje took place in the period 1960-1970 [4]. Specifically, in this area, in the sixties of the last century was located one third of the industrial plants in Macedonia which was a great appealing factor for the settlement of young and working population. This tends has stabilized around the eighties of the last century, mainly due to the weakened population strength of the villages.

During the period from 1981 to 1994 as a result of changes in the administrative-territorial division in the country, it is not possible to recognize changes in the volume of various types of internal migration, but based on several indications it has noted an increase of migrations between municipalities, particularly from city to city and within the area of the city of Skopje. Migration from rural to urban areas continued to unfold with reduced intensity, primarily due to the reduced population strength of the villages [10].

Significant internal displacement is recorded at the beginning of the 21 st century as a result of the war conflict in 2001. Specifically, the tensions between ethnic Macedonians and ethnic Albanians living in Macedonia grew into a war conflict in 2001 [9], whereas 76046 persons from areas affected by the conflict have moved to other parts of the country [6].

\section{METHODOLOGY AND DATA SOURCE}

Under the term internal migration is understood migration within a country and they may be voluntary or may have forced character.

Due to the changes in the administrative-territorial organization of the country, a special attention is given to the migration movements in the period 2000-2014. In the Republic of Macedonia, according to administrative-territorial organization from 2004 year, a total number of 84 municipalities are determined, and with the changes in 2013 their number was reduced to 80 municipalities. The reviewing of data by regions, it was, according to the NUTS 3 classifications, where eight statistical-planning regions were singled out. In the paper are used database of the State Statistical Office, by census periods, publications and highlighted series data. In the analysis of internal migration are taken into account internal migration within a municipality (local) and from one municipality to another (between municipalities), while among regions, it is not covered the displacement from one municipality towards another within the region.

The paper takes into account net migration represented as the difference between immigration in a certain area and emigration of the same area during a specified time interval [7]. 


\section{RESULTS AND DISCUSSION}

During the 21 st century internal migration had continued development pace, although their volume decreased mainly due to the intensification of emigration abroad as a result of the unfavourable socioeconomic situation in the country. In the period from 2000 to 2014 in the internal migration movements were involved 144245 persons, or an average of nearly 9616 persons per year. In local migrations were involved 27217 or $18.9 \%$, while $81.1 \%$ were involved in the migrations between municipalities.

In 2014 compared to 2000 internal migration dropped by $33.5 \%$. The reduction of $16.3 \%$ was recorded from 2000 to 2001, then -12,1\% in 2006-2007 and in the period of recession from 2008 to 2009 they decreased by $13.2 \%$. Followed in the fifteen year long period of analysis, the participation of local migrants and migrants involved in the migration between municipalities in the immigrated population decreases i.e. increases.

The main direction is from the underdeveloped and economically less developed areas to economically more developed.

Over $80 \%$ of all migrants are aged between 20 and 59 years. The figures show a pronounced feminization in these migrations because over $70 \%$ of all internal migrants are women and $80 \%$ of them are aged from 20 to 59 years. Over $40 \%$ of internal migrants moved because of marriage, and 30\% have done so, for family reasons. From other causes, an important meaning is given to the economic factor.

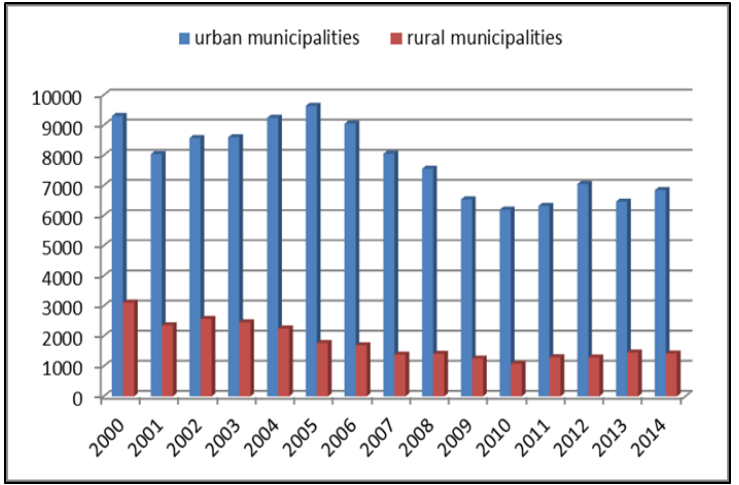

Figure 1. Internal migration movement in urban and rural municipalities in the Republic of Macedonia, 2000-2014

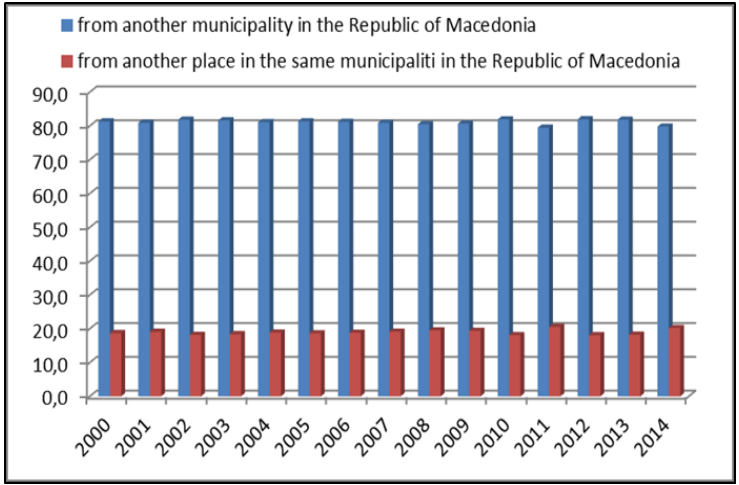

Figure 2. The structure of internal migration in the Republic of Macedonia, 2000-2014 (in \%)

Despite the increase in the share of local migrants in total internal migrations, compared to data from the nineties of the last century, it is evident that their participation reduces especially from rural to urban areas. It is certainly a consequence of the reduced population potential of the villages, as well as the pronounced migration from the rural area abroad [4]. In the period between 2000 and 2014 over $80 \%$ of the internal imigration took place in urban municipalities, although the number of internal imigrants in urban municipalities in 2014 compared to 2000 decreased by $26.4 \%$. In rural municipalities this reduction is more than 50\%. In the period from 2005 to 2014,53028 persons moved from the villages to the cities and from the cities to new urban settlements. Of the total number of migrants, $64.5 \%$ were moving from one city to another city, while $35.5 \%$ were moving from the villages to the city. From a total number of 18820 persons that moved from the villages to urban areas in the country, $51 \%$ were aged between 15 and 29 years, while $42 \%$ persons were aged 30 to 64 years. Only from 2013 to 2014 the number of people who migrated from rural to urban areas increased by $14.2 \%$ and the increase in those aged between 15 and 29 years was $12.8 \%$ and even $21.4 \%$ of migrants aged between 30 and 
64 years. In the period 2005-2014, for even $48.4 \%$ of all migrants involved in the internal migrations, Skopje was the new major living destination.

The main reason is the privilege of urban living, in particular, the rapid development of the secondary and service sectors in the city which enables an easy approach to a range of services and simplicity in carrying certain activities (education of children, health care, marriage, family issues, recreation, entertainment, culture).

A large part of rural municipalities confronted with a range of particularities due to its natural characteristics, problems of infrastructure modelling, economic marginalisation are not attractive for living and keeping the population, mostly, population in its fertile period, which puts into question the demographic sustainability of these areas.

An exception represents the rural municipalities in areas around major cities, that due to the proximity of the city and its contents are retained in the place of residence. Also, the proximity to the workplace in the city and the possession of agricultural land is an excellent opportunity to achieve double-income households. At the same time these areas are also attractive for the location of various other activities of commercial and non-profit sector, which changes the mono-functionality of space and keeps the workforce.

Table 1. Net migration of internal migration in the Republic of Macedonia in the period 2000-2014, by region

\begin{tabular}{rrrrrrrrr}
\hline Year & Skopje & Polog & Southwest & Pelagonia & Vardar & Northeast & East & Southeast \\
\hline $\mathbf{2 0 0 0}$ & 642 & -65 & -27 & -36 & -122 & -164 & -141 & -87 \\
\hline $\mathbf{2 0 0 1}$ & 578 & -144 & -41 & 24 & -134 & -102 & -115 & -66 \\
\hline $\mathbf{2 0 0 2}$ & 668 & -230 & -30 & 64 & -174 & -124 & -119 & -55 \\
\hline $\mathbf{2 0 0 3}$ & 577 & -206 & 12 & 0 & -62 & -167 & -97 & -57 \\
\hline $\mathbf{2 0 0 4}$ & 650 & -210 & -10 & -30 & -86 & -191 & -73 & -50 \\
\hline $\mathbf{2 0 0 5}$ & 614 & -112 & -54 & -26 & 161 & -152 & -102 & -7 \\
\hline $\mathbf{2 0 0 6}$ & 567 & -114 & -4 & -33 & -135 & -172 & -106 & -3 \\
\hline $\mathbf{2 0 0 7}$ & 650 & -123 & -15 & -31 & -140 & -167 & -129 & -45 \\
\hline $\mathbf{2 0 0 8}$ & 389 & -38 & 18 & -48 & -115 & -51 & -127 & -28 \\
\hline $\mathbf{2 0 0 9}$ & 596 & -88 & 3 & -74 & -117 & -111 & -158 & -51 \\
\hline $\mathbf{2 0 1 0}$ & 251 & 50 & 38 & -79 & -81 & -145 & -44 & 10 \\
\hline $\mathbf{2 0 1 1}$ & 596 & -58 & -6 & -131 & -69 & -138 & -191 & -3 \\
\hline $\mathbf{2 0 1 2}$ & 788 & -63 & 46 & -167 & -199 & -170 & -197 & -38 \\
\hline $\mathbf{2 0 1 3}$ & 682 & -34 & -37 & -127 & -60 & -151 & -209 & -64 \\
\hline $\mathbf{2 0 1 4}$ & 851 & -86 & -115 & -159 & -95 & -145 & -200 & -51 \\
\hline & Data source: Own calculations according to the State Statistical Office data; www.stat.gov.mk
\end{tabular}

On average, towards the Skopje region, from the territory of other regions are moving about 200 male and 407 female persons every year. Other regions are facing population loss through internal migrations, which is particularly emphasized by the negative values in the East and Northeast Region. Other regions vary with the values of net migration. Net migration among the female population has a more pronounced negative value in comparison to the male population, with the exception of the Polog region. 


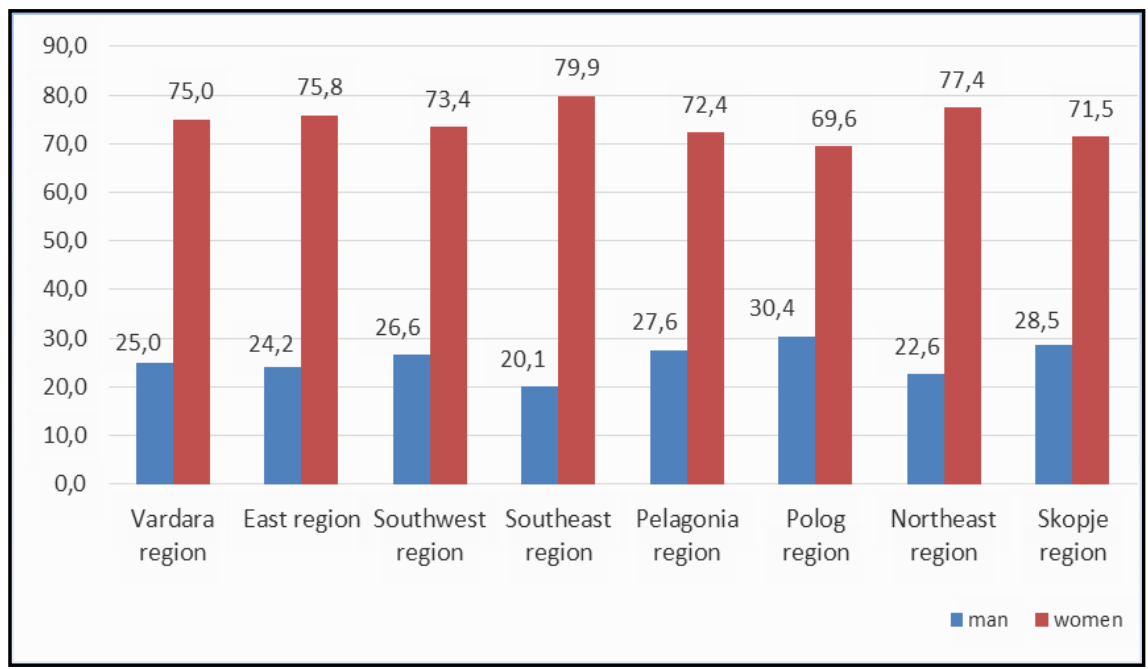

Figure 3: Structure of internal migrants by sex, in the period 2000-2014, in \%

Table 2. Net migration in internal migration in the Republic of Macedonia by sex, in the period 2000-2014, by regions

\begin{tabular}{|c|c|c|c|c|c|c|c|c|c|c|c|c|c|c|c|c|}
\hline \multirow{2}{*}{ year } & \multicolumn{2}{|c|}{ Vardar } & \multicolumn{2}{|c|}{ East } & \multicolumn{2}{|c|}{ Southwest } & \multicolumn{2}{|c|}{ Southeast } & \multicolumn{2}{|c|}{ Pelagonia } & \multicolumn{2}{|c|}{ Polog } & \multicolumn{2}{|c|}{ Northeast } & \multicolumn{2}{|c|}{ Skopje } \\
\hline & male & female & male & female & male & female & male & female & male & female & male & female & male & female & male & female \\
\hline 2000 & -42 & -80 & -32 & -109 & -20 & -7 & 6 & -93 & -35 & -1 & -53 & -12 & -43 & -121 & 219 & 423 \\
\hline 2001 & -35 & -99 & -20 & -95 & -7 & -34 & -1 & -65 & 0 & 24 & -67 & -77 & -33 & -69 & 163 & 415 \\
\hline 2002 & -46 & -128 & -34 & -85 & -7 & -23 & -5 & -50 & 21 & 43 & -116 & -114 & -52 & -72 & 239 & 429 \\
\hline 2003 & -23 & -39 & -18 & -79 & 5 & 7 & 2 & -59 & -4 & 4 & -109 & -97 & -40 & -127 & 187 & 390 \\
\hline 2004 & -26 & -60 & -19 & -54 & 6 & -16 & 20 & -70 & -7 & -23 & -114 & -96 & -56 & -135 & 196 & 454 \\
\hline 2005 & -30 & -131 & -9 & -93 & -29 & -25 & 25 & -32 & -30 & 4 & -73 & -39 & -37 & -115 & 183 & $\overline{431}$ \\
\hline 2006 & -43 & -92 & -30 & -76 & 5 & -9 & 14 & -17 & -10 & -23 & -70 & -44 & -43 & -129 & 177 & 390 \\
\hline 2007 & -46 & -94 & -22 & -107 & 10 & -25 & 2 & -47 & -37 & 6 & -91 & -32 & -45 & -122 & 229 & 421 \\
\hline 2008 & -32 & -83 & -31 & -96 & -8 & 26 & 22 & -50 & -8 & -40 & -70 & 32 & -17 & -34 & 144 & 245 \\
\hline 2009 & -43 & -74 & -55 & -103 & -11 & 14 & 20 & -71 & -34 & -40 & -43 & -45 & -30 & -81 & 196 & $\overline{400}$ \\
\hline 2010 & -18 & -63 & -3 & -41 & 16 & 22 & 23 & -13 & -35 & -44 & -14 & 64 & -25 & -120 & 56 & 195 \\
\hline 2011 & -30 & -39 & -36 & -155 & 7 & -13 & 7 & -10 & -53 & -78 & -47 & -11 & -15 & -123 & 167 & 429 \\
\hline 2012 & -34 & -165 & -82 & -115 & 41 & 5 & 1 & -39 & -67 & -100 & -68 & 5 & -57 & -113 & 266 & 522 \\
\hline 2013 & -2 & -58 & -84 & -125 & -4 & -33 & -9 & -55 & -35 & -92 & -52 & 18 & -55 & -96 & 241 & 441 \\
\hline 2014 & -41 & -54 & -81 & -119 & -52 & -63 & -16 & -35 & -34 & -125 & -48 & -38 & -52 & -93 & 324 & 527 \\
\hline
\end{tabular}

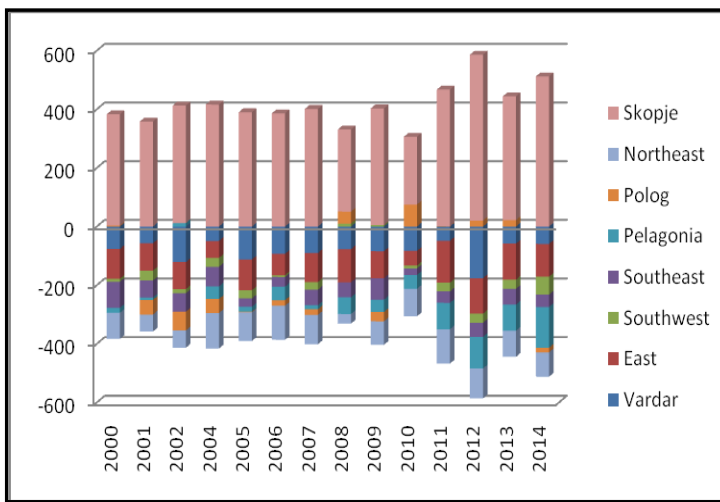

Figure 4. Total female fertile population involved in the internal migrations, by regions

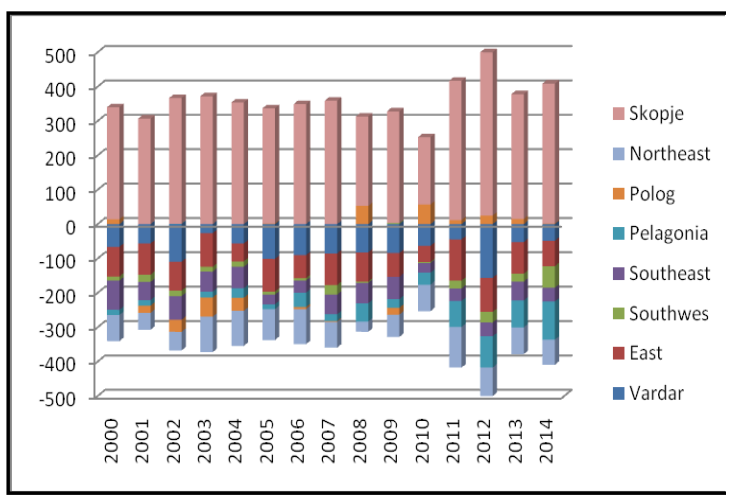

Figure 5. Optimal female fertile contingent (from 20-34 years), involved in the internal migrations, by regions 
Of the total female population, participating in internal migration movements, $81 \%$ are in their fertile period, of which $84 \%$ are at the optimal fertile age from 20 to 34 years. Especially alarming is the fact that the displacement of the female population at the fertile age dominates in all regions, although in some regions such as the East and Vardar region, this phenomenon is more pronounced.

Skopje and its surroundings according to its location, infrastructure equipment has all the necessary conditions for an economically sustainable development. Indicators suggest that in the first years of the 21st century, nearly half of the total investment in fixed assets in the industry was realized in Skopje Valley, while in the industry were employed one third of the total number of industry workers in the Republic of Macedonia [1].

In 2010, half of the total gross fixed capital formation, and nearly $40 \%$ of the total business entities are recorded in the Skopje region (half of the medium - sized and over $70 \%$ of large enterprises). That is more than 3.5 times in comparison to the Pelagonija region, as a second in the number of business subjects, or nearly 7 times more than the Northeast region. At the same time, over $1 / 3$ from the total investments in the industrial sector in the Republic of Macedonia are in this region [8]. In 2012 the Skopje Region had the highest GDP per capita (327989 denars) compared to the other regions, and it participated with $42.8 \%$ in the total GDP of the Republic of Macedonia.

In 2014 the highest average monthly net wage paid per employee, compared to the overall average in the Republic of Macedonia, was observed in the Skopje Region (18.1\%), while the lowest average monthly net wage paid per employee in the same year, compared to the overall average in the Republic of Macedonia, was recorded in the East Region $(26.2 \%)$.

Accompanied with the largest share of vacant positions compared to other regions, and the shape of the area, including the contents of the social and cultural life is an argument more in favour of the attractiveness of the region for settlement and not preventing its demographic and sustainable economic development. The highest frequency in the migratory movements is recorded in the Skopje city municipalities such as Aerodrom, Kisela Voda, Karposh and Center. In the analysed period in these municipalities took place over half of the total internal migrations between municipalities. Specifically, the intensive residential construction in certain parts of the city as Aerodrom, Kisela Voda, Karposh and Centre, combined with favourable conditions offered for buying its own home, contributed to the greater concentration of young reproductive population. In the past few years, banks in the country for the customers presented a more favourable credit terms when buying a home. At the same time, this coincided with the measures taken by the Government for the project "Buy a House, Buy a Flat", where young couples were offered financial assistance, favourable interest rates and generally favourable repayment terms.

On the other hand, Skopje region on a daily basis faces problems because of the functional changes in land use, which in part represented an agricultural land with solid pedological characteristics, as well as problems regarding the quality of the environment. In the period from 2008 to 2014, 29\% of all construction approvals, a third of all business entity approvals and a quarter of all individuals have been recorded in the Skopje region. At the same time in this region are realized over one third of all completed dwellings in the country. The over adjusted residential construction contributed density of 339.7 inhabitants per $\mathrm{km}^{2}$ in 2014, which is over 4 times higher compared to the average population density in the country, and about 10 times higher compared to the Vardar 
region. In 2014, at only $7 \%$ of the territory of the Republic of Macedonia lived nearly $30 \%$ of the population in the country.

This type of demographic polarization significantly affects the sustainable quality of the environment in this area.

Skopje Valley, which already applies to be the valley with the highest number of foggy days, now faces an even greater problem with the appearance of fog. Concentrations of carbon monoxide, nitrogen dioxide, and concentrations of suspended particles in the ambient air in Skopje, are several times above the maximum limit mainly in the winter period due to the weather conditions and the occurrence of stable weather.

\section{CONCLUSION}

Internal migration in collaboration with emigration abroad of course, significantly affects their ability for sustainable development. The uneven distribution of population complicates the intention for spatial, economic and demographic development planning, while also causes environmental pollution. The problems are present in urban and rural areas. The fact that nearly half of all internal migration movements are directed towards Skopje, opened a number of new effects examined from the angle of the quality of life and optimal capacity for the quality of life in the capital and in the Skopje region. Skopje city municipalities have been inhabited over the optimum limit for a long time. All their spatial and population strengthening, reflects the quality of the environment and citizens health.

On the other hand, a large part of rural municipalities are facing marginal development and untapped resources, which of course has an effect on the overall economy.

Certainly there are many conceptual designs and suggestions that can contribute to the strengthening of the pull factors in rural municipalities. Primarily, it should be approached to improve the infrastructural base, changing the monofunctional character of functional development (introduction of modern and intensive agricultural and livestock production, locating commercial facilities, non-profit facilities and accommodation capacities for the tourism needs). This list of contents will absorb the surplus of labour force in the agriculture. The greater concentration of functions and population mass, would allow an increase in the attractive force of the settlement and the sphere of influence of local character [2]. It can all then take place according to the gravitational model because "the greater the centre is, the greater its attractive force is; its attractive force is weakening with the growing distance between them and other population centres" [11]. The organs of the state and local authority should act simulative and preventive in the affected areas in order to provide appropriate demographic and economic growth and balance. The processes that are going on these recent years emphasize the need for changes in the territorial - administrative organization of the area. This will strengthen the hierarchical status of the individual settlements and their competence in organizing and planning the space to meet the needs of the individual and the society [3]. At the same time, a positive "brake" on internal migration movements to the city and especially in the city of Skopje are the measures on subsidies in agriculture as well as the announced designs for changing the course of internal migration movements from the city to the countryside by subsidizing young people who will decide to live in the village. 


\section{REFERENCES}

[1] Apostolovska Toshevska B., Industry and sustainable development, Proceedings of the scientific symposium with international participation, "Geography and sustainable development", 22-25.10.2009, Ohrid, Republic of Macedonia, pp 253-267;

[2] Apostolovska Toshevska B. \& Iliev D. Infrastructure as a factor of economicgeographical and functional development of hilly, hilly-mountainous and mountainous village settlement in the catchment area of Babuna and Topolka, Proceedings from the International scientific symposium "Hilly mountain areas - problems and perspectives", 12-15. 09. 2013, Ohrid, Republic of Macedonia, pp 275-282;

[3] Apostolovska Toshevska B. \& Madjevikj M., Demographic components of the Pelagonija region as benchmarks in the formation of the labour contingent, Demography: international journal for demographic and other social studies, No. 9, Faculty of Geography, University of Belgrade, Serbia, 2012, pp 289-300;

[4] Bornarova S. \& Janeska V. Social Impact of Emigration and Rural-Urban Migration in Central and Easter Europe: Final Report - European Commission, DG Employment, Social Affairs and Inclusion- GVG, 2012;

[5] Dimitrieva E., Janeska V. \& Hinic B., Les mouvements migratoires (internes et internationaux) et la répartition spatiale de la population dans l'ancienne République Yougoslave de Macédoine, in: Kotzamanis, B., Mouvements migratoires et la répartition spatiale de la population, La démographie des Balkans, Université de Thessalie Université de Macédoine Réseau DémoBalk. Volos, Greece, 2000;

[6] Joveski, B. Z., Forms of illegal and forced migration in the Republic of Macedonia, Security dialogues, 314.15.045:343.85 (497.7), on line, 2010, pp 59-74;

[7] Kjurchiev A., Dimitrieva E., Jovanovikj A., Janeska V. \& Lozanoska A., Demographic terminological glossary, University "St. Cyril and Methodius", Institute of Economics, Skopje, Republic of Macedonia, 2011, pp 167;

[8] Madzevikj M., Apostolovska Toshevska B. \& Iliev D. Process of population and economical polarization in Republic of Macedonia, Geografika Pannonika, 2013;

[9] Mitrevska M. et al., Prevention and conflict management: the case of Macedonia: (a new security paradigm), Skopje, Bomat grafiks, 2009;

[10] Risteski S. \& Trpkova Nestorovska M., Demography, methods and analysis, Faculty of Economics, Skopje, Republic of Macedonia, 2014;

[11] Selmani A., An attempt to construct a new territorial organization of the Republic of Macedonia, Proceedings of the round table discussion on the territorial organization of municipalities as a basis for future development of the Republic of Macedonia, Faculty of natural sciences and mathematics, Institute of Geography, Skopje, 2004

[12] Stojmilov A., Socioeconomic geography of the Republic of Macedonia, Faculty of natural sciences and mathematics, Skopje, Republic of Macedonia, 2005, pp 126 